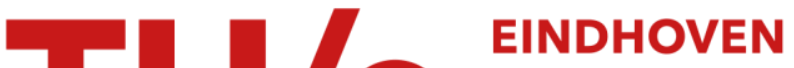 UNIVERSITY OF TECHNOLOGY
}

\section{Consideration of the impacts of a smart neighborhood load on transformer aging}

Citation for published version (APA):

Paterakis, N. G., Pappi, I. N., Erdinç, O., Godina, R., Rodrigues, E. M. G., \& Catalão, J. P. S. (2016).

Consideration of the impacts of a smart neighborhood load on transformer aging. IEEE Transactions on Smart

Grid, 7(6), 2793-2802. https://doi.org/10.1109/TSG.2015.2501380

\section{Document license:}

TAVERNE

DOI:

10.1109/TSG.2015.2501380

Document status and date:

Published: 01/11/2016

\section{Document Version:}

Publisher's PDF, also known as Version of Record (includes final page, issue and volume numbers)

\section{Please check the document version of this publication:}

- A submitted manuscript is the version of the article upon submission and before peer-review. There can be important differences between the submitted version and the official published version of record. People interested in the research are advised to contact the author for the final version of the publication, or visit the $\mathrm{DOI}$ to the publisher's website.

- The final author version and the galley proof are versions of the publication after peer review.

- The final published version features the final layout of the paper including the volume, issue and page numbers.

Link to publication

\section{General rights}

Copyright and moral rights for the publications made accessible in the public portal are retained by the authors and/or other copyright owners and it is a condition of accessing publications that users recognise and abide by the legal requirements associated with these rights.

- Users may download and print one copy of any publication from the public portal for the purpose of private study or research.

- You may not further distribute the material or use it for any profit-making activity or commercial gain

- You may freely distribute the URL identifying the publication in the public portal.

If the publication is distributed under the terms of Article 25fa of the Dutch Copyright Act, indicated by the "Taverne" license above, please follow below link for the End User Agreement:

www.tue.nl/taverne

Take down policy

If you believe that this document breaches copyright please contact us at:

openaccess@tue.nl

providing details and we will investigate your claim. 


\title{
Consideration of the Impacts of a Smart Neighborhood Load on Transformer Aging
}

\author{
Nikolaos G. Paterakis, Member, IEEE, Iliana N. Pappi, Ozan Erdinç, Member, IEEE, Radu Godina, \\ Eduardo M. G. Rodrigues, and João P. S. Catalão, Senior Member, IEEE
}

\begin{abstract}
Smart grid solutions with enabling technologies such as energy management systems (EMSs) and smart meters promote the vision of smart households, which also allows for active demand side in the residential sector. These technologies enable the control of residential consumption, local small-scale generation, and energy storage systems to respond to time-varying prices. However, shifting loads simultaneously to lower price periods is likely to put extra stress on distribution system assets such as distribution transformers. Especially, additional new types of loads/appliances such as electric vehicles (EVs) can introduce even more burden on the operation of these assets, which is an issue that needs special attention. Such extra stress can cause accelerated aging of distribution system assets and significantly affect the reliability of the system. In this paper, the impact of a smart neighborhood load on distribution transformer aging is investigated. The EMS of each household is designed to respond to prices and other signals emitted by the responsive load serving entity within the relevant demand response strategy. An optimization framework based on mixed-integer linear programming is presented in order to define the EMS structure. Then, the equivalent aging of the distribution transformer is examined with a thermal model under different scenarios. The case studies that are presented indicate that the integration of EVs in residential premises may indeed cause accelerated aging of the distribution transformers, while the need to investigate the efficiency of dynamic pricing mechanisms is rendered evident.
\end{abstract}

Manuscript received May 16, 2015; revised July 23, 2015 and October 8, 2015; accepted November 14, 2015. Date of publication December 3, 2015; date of current version October 19, 2016. This work was supported in part by FEDER funds through COMPETE; in part by the Portuguese funds through FCT under Grant FCOMP-01-0124-FEDER-020282 (Ref. PTDC/EEA-EEL/118519/2010), Grant UID/CEC/50021/2013, and Grant SFRH/BPD/103744/2014; in part by the Scientific and Technological Research Council of Turkey under Project 115E215; and in part by the EU Seventh Framework Programme FP7/2007-2013 under Grant 309048 (project SiNGULAR). Paper no. TSG-00552-2015.

N. G. Paterakis is with the Department of Electrical Engineering, Eindhoven University of Technology, Eindhoven 5600 MB, The Netherlands (e-mail: n.paterakis@tue.nl).

I. N. Pappi, R. Godina, E. M. G. Rodrigues, and J. P. S. Catalão are with the Faculty of Engineering, University of Porto, Porto 4200-465, Portugal, also with the University of Beira Interior, Covilhã 6200-001, Portugal, and also with the INESC-ID, Instituto Superior Técnico, University of Lisbon, Lisbon 1049-001, Portugal (e-mail: iliananpappi@gmail.com; radugodina@gmail.com; erodrigues0203@gmail.com; catalao@ubi.pt).

O. Erdinç is with Yildiz Technical University, Istanbul 34220, Turkey, and also with the INESC-ID, Instituto Superior Técnico, University of Lisbon, Lisbon 1049-001, Portugal (e-mail: oerdinc@yildiz.edu.tr; ozanerdinc@gmail.com).

Color versions of one or more of the figures in this paper are available online at http://ieeexplore.ieee.org.

Digital Object Identifier 10.1109/TSG.2015.2501380
Index Terms-Distributed generation, energy management system, electric vehicle, smart neighborhood, transformer aging.

\section{NOMENCLATURE}

$\begin{array}{ll}\text { Abbreviations } \\ D R & \text { demand response. } \\ D S & \text { distribution system. } \\ E M S & \text { energy management system. } \\ E S S & \text { energy storage system. } \\ E S S 2 H & \text { energy storage system-to-home. } \\ E V & \text { electric vehicle. } \\ M I L P & \text { mixed-integer linear programming. } \\ P V & \text { photovoltaic. } \\ P V 2 H & \text { photovoltaic-to-home. } \\ V 2 H & \text { vehicle-to-home. } \\ V 2 G & \text { vehicle-to-grid. }\end{array}$

Indices

$h \quad$ smart household index.

$t \quad$ period of the day index in time units [h].
Variables
Cost $_{h}$
total electrical consumption cost for each smart household of the neighborhood.
$K \quad$ load factor (load current/rated current).
$P_{h, t}^{\text {grid }}$
$P_{h, t}^{P V, \text { used }}$
power drawn from the grid by each house- hold $[\mathrm{kW}]$.
$P_{h, t}^{E V, u s e d}$
PV power used by the household [kW].
$P_{h, t}^{E S S, \text { used }}$
$P_{h, t}^{E V, c h}$
$P_{h, t}^{E S S, c h}$
V
$V_{n}$
$\theta_{h}$
$\theta_{o}$
$\triangle \theta_{o, i}$ power of EV battery used by the house- hold $[\mathrm{kW}]$. power of ESS used by the household [kW].
charging power of $\mathrm{EV}[\mathrm{kW}]$.
charging power of ESS [kW].
relative aging rate.
relative aging rate during interval $n$.
winding hottest-spot temperature $\left[{ }^{\circ} \mathrm{C}\right]$.
top-oil temperature $\left[{ }^{\circ} \mathrm{C}\right]$.
top-oil (in tank) temperature rise at start $\left[{ }^{\circ} \mathrm{K}\right]$. 


\section{Parameters}

$g_{r}$

$H$

$k_{11}$

$k_{21}$

$k_{22}$

$N$

$P_{h, t}^{\text {in }}$

$P_{r}$

$R$

$\theta_{a}$

$x$

$y$

$\triangle \theta_{o, r}$

$\triangle \theta_{h, i}$

$\triangle \theta_{h, r}$

$\lambda_{t}^{\text {buy }}$

$\tau_{O}$

$\tau_{w}$ average winding to average oil (in tank) temperature gradient at rated current $\left[{ }^{\circ} \mathrm{K}\right]$.

hot-spot factor.

thermal model constant.

thermal model constant.

thermal model constant.

total number of time intervals.

inelastic electrical load for each household [kW].

distribution transformer rated power [kW].

ratio of load loss to no-load loss at rated current.

the ambient temperature $\left[{ }^{\circ} \mathrm{C}\right]$.

exponential power of total losses versus top-oil

(in tank) temperature rise (oil exponent).

exponential power of current versus winding

temperature rise (winding exponent).

top-oil temperature rise at rated current $\left[{ }^{\circ} \mathrm{K}\right]$.

hot-spot-to-top-oil (in tank) gradient at

start $\left[{ }^{\circ} \mathrm{K}\right]$.

hot-spot temperature rise at rated current $\left[{ }^{\circ} \mathrm{K}\right]$.

buying price of electrical energy from grid [cents/kWh].

average oil time constant.

winding time constant.

\section{INTRODUCTION}

D ISTRIBUTION system (DS), that serves as the bridge between transmission system and end-user premises for electric energy transfer, is considered as one of the most important points of a power system for the effective and efficient utilization of electricity. With the introduction of different kinds of electric loads on the market, the load shapes of enduser premises have started to change significantly, a fact that may lead to compelling circumstances for DS assets such as transformers, lines, etc.

As a new type of end-user appliance/load, electric vehicles (EVs) have recently gained more importance as the electrification of the transport sector, which traditionally is a major fossil fuel consumer, is promoted [1]. EVs differ from the traditional loads, in the sense that they may both consume and provide energy, posing challenges and offering opportunities that should be examined in detail [2], [3]. On the one hand, from the perspective of a load, the energy needs of EVs can reach the levels of new power plant installation requirements. For example, the recommended charging level of a Chevy Volt, a small sized EV, is $3.3 \mathrm{~kW}$, which can even exceed the total installed power of many individual homes in an insular area [4]. On the other hand, EVs can also be employed as a system resource, especially during peak periods through the vehicle-to-home (V2H) and vehicle-to-grid (V2G) options [5], [6].

Apart from EVs, non-dispatchable distributed generation technologies such as photovoltaic systems (PV) and wind energy conversion systems increase the uncertainty in the daily operation of the DS.

Herein, transformers, considered as core elements of DS, are given specific importance in industrial applications in order to increase the reliability of DS operation under high penetration levels of the aforementioned technologies in the DS. Transformers are significantly affected by operating conditions such as heavy loading and therefore it is important to evaluate the effects of possible extra loads that can have such impacts on transformer units. The transformer operating lifetime is normally declared by manufacturers under normal operating conditions. However, operating conditions beyond the nominal are likely to cause a decrement in the effective operating lifetime of a transformer unit, especially due to increased thermal load causing insulation aging (which depends on winding temperature). Thus, it is important to maintain the transformer's operating conditions within certain limits to ensure longer operation of this pivotal asset of DS. With this aim, "smart grid" solutions that are recently gaining increasing importance are likely to be applied in order to prolong the effective utilization period of such assets.

The "smart" grid has been considered to have a prominent position within the new concepts for operating the mature electric power grid in a more efficient and reliable way, that is also supported by high levels of investments from governments of both developed and developing countries. Within the smart grid concept, smart home structures together with smart home energy management systems (EMS) capable of controlling home size distributed energy production facilities, EV based storage/production options, and controllable new generation smart appliances have also been the specific topic of some research activities in the area of residential demand-side management [7]-[13].

Specifically considering smart solutions in the DS areas for the effective utilization of transformers, the impact of EV charging on the distribution transformers was studied in [14]. Randomized plug-in time, random departure time, and battery charging characteristics as well as the control and optimization of the EV charging were neglected and presented as the aim of future studies in [14]. Besides, [14] solely considered the impacts of EVs under several scenarios without taking into account any other end-user characteristics. Moreover, [14] neglected the V2G possibility that can raise issues in terms of the magnitude and the duration of transformer overloading. As an extension of the study presented in [14], Vicini et al. [15] also considered the coordination of EV charging activities within a neighborhood via home EMS, considering incentive based demand response (DR). However, in [15] no issue related to the minimization of individual home owner daily electric energy costs was taken into account. Besides, in [15] the V2G possibility is neglected. A method for describing the EV charging effects on overhead distribution transformers and a method for mitigating this impact through a transformer temperature-based smart charging algorithm provided to reduce transformer overloading was proposed in [16]. However, this study neglected the individual home owner cost minimization. There are also other studies, not mentioned here, that have provided important insights on the area. However, none of them considered the impact of a time-varying DR scheme on the aging of a distribution transformer serving a residential neighborhood. Such considerations are important in order to investigate potential tradeoffs between the 


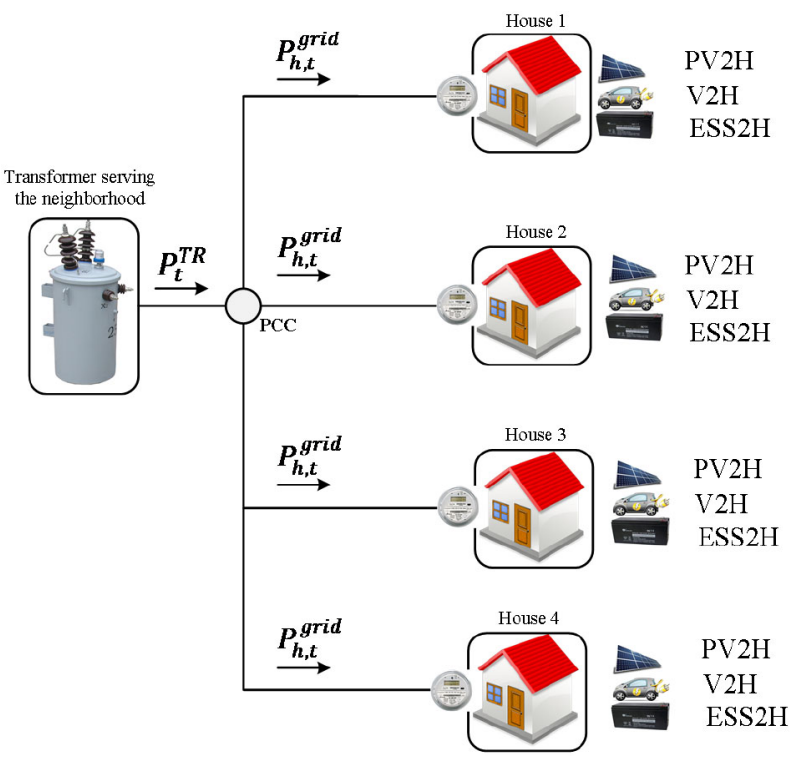

Fig. 1. Schematic diagram of a transformer serving a neighborhood composed of 4 smart households.

benefits that emerge from rendering available dynamic tariffs to residential end-users and the inefficient utilization of the DS infrastructure.

In this study, the impact of the operation of a neighborhood of smart households contracted under a time-varying pricing scheme on the local distribution transformer aging is studied, which has not yet been considered in the relevant literature. The investigation of this issue constitutes the major contribution of the paper.

Furthermore, the effect of the possibility of EVs to cover a portion of the household load through $\mathrm{V} 2 \mathrm{H}$ mode is analyzed as well. The aim of the numerical simulations is to demonstrate that the integration of EVs may indeed accelerate the aging of the distribution transformers and to investigate the efficiency of the dynamic pricing scheme.

The remainder of the paper is organized as follows: in Section II the proposed methodology is developed. Then, in Section III a realistic test case is presented and the obtained results are thoroughly discussed. Finally, conclusions are drawn in Section IV.

\section{Methodology}

The schematic diagram of a transformer serving a neighborhood composed of multiple smart households is depicted in Fig. 1.

\section{A. Minimization of the Cost of Each Individual Household}

The equations concerning the smart-household appliances are given below as part of the model of optimizing the cost for electricity usage for each smart household.

The objective of each household $h$ is to minimize the cost of buying energy from the grid. This is expressed by (1).

$$
h \in H: \text { Minimize } \text { Cost }_{h}=\sum_{t}\left(P_{h, t}^{\text {grid }} \cdot \Delta T \cdot \lambda_{t}^{\text {buy }}\right)
$$

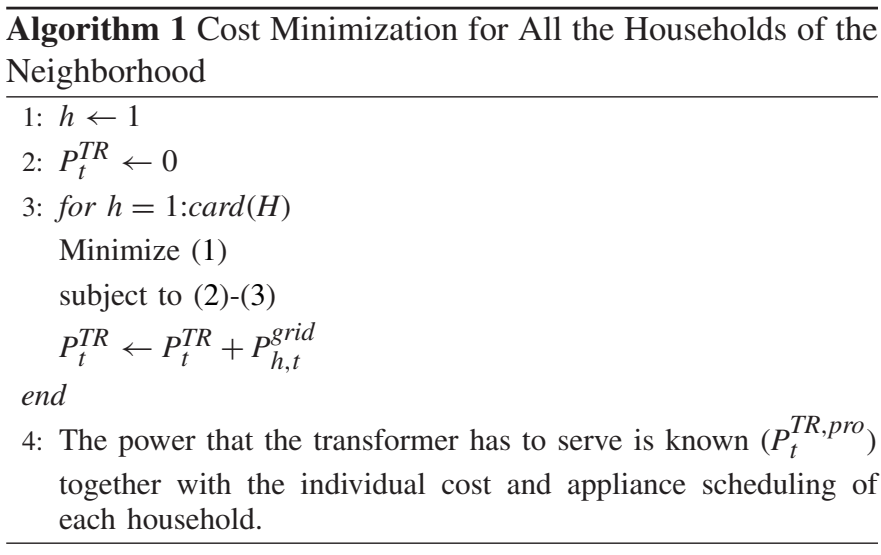

In (1), $P_{h, t}^{\text {grid }}$ is the power drawn from the grid $(\mathrm{kW})$ from household $h$ in period $t, \Delta T$ is the duration of the optimization interval (h) and $\lambda_{t}^{\text {buy }}(€ / \mathrm{kWh})$ is the hourly varying price signal. The electricity price is assumed to be the same for all the houses fed by the transformer.

The power balance for each household is:

$$
\begin{aligned}
h \in H: P_{h, t}^{\text {grid }}+P_{h, t}^{P V, \text { used }}+P_{h, t}^{E V, \text { used }}+P_{h, t}^{E S S, \text { used }} \\
=P_{h, t}^{i n}+P_{h, t}^{E V, c h}+P_{h, t}^{E S S, c h}, \quad \forall t
\end{aligned}
$$

The amount of energy consumed to cover the needs of each smart household includes the inelastic load used by all the appliances of the house $\left(P_{h, t}^{i n}\right)$, the charging needs of the ESS of the household $\left(P_{h, t}^{E S S, c h}\right)$ and also the charging needs of the EV battery $\left(P_{h, t}^{E V, c h}\right)$. This total amount of electricity consumption is covered, for each household, either by power drawn from the grid through the distribution transformer $\left(P_{h, t}^{g r i d}\right)$, or by the power produced by the PV installation $\left(P_{h, t}^{P V, u s e d}\right)$, or the power stored in the $\operatorname{ESS}\left(P_{h, t}^{E S S, \text { used }}\right)$ and the $\operatorname{EV}\left(P_{h, t}^{E V \text {, used }}\right)$.

The EV and ESS modeling includes the equations and constraints which have been presented and explained in detail in [4] and [17]. These constraints are represented by the general expression (3) in which $\overline{\boldsymbol{x}}_{h}$ is the vector of the decision variables pertaining the constraints of each household $h$, while $S_{h}$ is the set of feasible solutions.

$$
h \in H: \overline{\boldsymbol{x}}_{h} \in S_{h} \forall t
$$

The optimization of the smart household is performed through Algorithm 1.

The EMS of each smart household solves its own appliance scheduling problem in a decentralized fashion. Then, the transformer monitoring unit receives the information regarding the request of power by the neighborhood and calculates the equivalent aging.

\section{B. Transformer Aging Effect Modeling}

1) Loss of Life Calculations: A proper preservation of mineral-oil-tilled distribution transformers is of a key importance in power systems, and therefore, there is the need to adopt a caring approach concerning transformer loading, 
in order to benefit as much as possible from their availability and life service.

The insulation of a power transformer is essentially made of paper and oil which suffers from aging. Unexpected rise of the load results in a rise in the hot-spot temperature and subsequently affects the thermal decomposition of [18]-[20].

Since the temperature distribution is not uniform, the hottest section of the transformer will consequently be the most damaged. Thus, the hot-spot temperature directly affects the life duration of transformers [21], [22].

The rate at which the aging of paper insulation for a hotspot temperature is increased or decreased compared to the aging rate at a reference hotspot temperature [18] is the relative aging rate $V$, which is the rate at $110{ }^{\circ} \mathrm{C}$ according to [19].

The relative aging rate for the thermally upgraded paper, that is chemically modified to improve the stability of the cellulose structure, is above one for hot-spot temperatures greater than $110{ }^{\circ} \mathrm{C}$ and means that the insulation ages many times faster compared to the aging rate at a reference hotspot temperature, while it is lower than one for hot-spot temperatures less than $110{ }^{\circ} \mathrm{C}$ [16]. For thermally upgraded paper the relative aging rate $V$ is given by (4) [19].

$$
V=e^{\left(\frac{15000}{110+273}-\frac{15000}{\theta_{h}+273}\right)}
$$

Over a certain period of time, the loss of life $L$ is calculated using (5).

$$
L=\int_{t_{1}}^{t_{2}} V d t \text { or } L \approx \sum_{n=1}^{N} V_{n} \times t_{n}
$$

2) Hot-Spot Temperature in Transient Conditions: The key idea behind the top-oil temperature rise model is that an increase in the losses is a result of an increase in the loading of the transformer and subsequently the global temperature of the transformer.

The temperature fluctuations are dependent on the overall thermal time constant of the transformer, which in turn depends on the rate of heat transfer to the environment and the thermal capacity of the transformer.

In steady state, the total transformer losses are proportional to the top-oil temperature rise. In transient conditions, the hotspot temperature is described as a function of time, for varying load current and ambient temperature [18].

The temperature rise of the oil may be modeled as a capacitance in the RC circuit, so that the heat transfer equations are expressed as exponential functions, taking into account the charge and discharge of an equivalent RC circuit.

For an increasing step of loads, the top-oil and winding hot-spot temperatures rise to a level corresponding to a load factor of $K$. In this case, the top-oil temperature is defined by (6) and (7).

$$
\begin{aligned}
\theta_{o}(t)=\triangle \theta_{o, i}+ & \left\{\theta_{o, r} \times\left[\frac{1+R \times K^{2}}{1+R}\right]^{x}-\Delta \theta_{o, i}\right\} \\
& \times\left(1-e^{-t /\left(k_{11} \times \tau_{o}\right)}\right)
\end{aligned}
$$

\begin{tabular}{|c|c|c|}
\hline Symbol & Value & Units \\
\hline$g_{r}$ & 14.5 & $\mathrm{Ws} / \mathrm{K}$ \\
\hline$H$ & 1.4 & - \\
\hline$k_{11}$ & 1 & - \\
\hline$k_{21}$ & 1 & - \\
\hline$k_{22}$ & 2 & - \\
\hline$P_{r}$ & 25 & $\mathrm{~kW}$ \\
\hline$R$ & 8 & - \\
\hline$x$ & 0.8 & - \\
\hline$y$ & 1.6 & - \\
\hline$\Delta \theta_{o, r}$ & 20.3 & ${ }^{\circ} \mathrm{K}$ \\
\hline$\tau_{o}$ & 180 & $\min$ \\
\hline$\tau_{w}$ & 10 & $\min$ \\
\hline \multicolumn{3}{|c|}{$\begin{aligned} \Delta \theta_{h}(t)= & \Delta \theta_{h, i}+\left\{H \times g_{r} \times K^{y}-\triangle \theta_{h, i}\right\} \\
& \times\left[k_{21} \times\left(1-e^{-t /\left(k_{22} \times \tau_{w}\right)}\right)-\left(k_{21}-1\right)\right.\end{aligned}$} \\
\hline
\end{tabular}

TABLE I

TRANSFORMER PARAMETERS

For a decreasing step of loads, the top-oil and winding hot-spot temperatures decrease to a level corresponding to a load factor of $K$ [18]. In this case, the top-oil temperature is calculated by (8) and (9).

$$
\begin{aligned}
\theta_{o}(t)=\Delta \theta_{o, r} & \times\left[\frac{1+R \times K^{2}}{1+R}\right]^{x} \\
& +\left\{\Delta \theta_{o, i}-\Delta \theta_{o, r} \times\left[\frac{1+R \times K^{2}}{1+R}\right]^{x}\right\} \\
& \times\left(e^{-t /\left(k_{11} \times \tau_{o}\right)}\right) \\
\triangle \theta_{h}(t)=H \times g_{r} & \times K^{y}
\end{aligned}
$$

In conclusion, with $\theta_{o}(t)$ and $\triangle \theta_{h}(t)$ obtained using (6) and (7) for increasing load steps, or (8) and (9) for decreasing load steps, the overall hot-spot temperature equation is (10).

$$
\theta_{h}(t)=\theta_{a}+\theta_{o}(t)+\triangle \theta_{h}(t)
$$

\section{TESTS AND RESULTS}

\section{A. Input Data}

The mathematical model of the smart households described above has been implemented in GAMS v.24.1.3. and was solved using the commercial solver CPLEX v.12. The utilized optimization interval is 4 minutes $(0.066 \mathrm{~h})$ and as a result there are 360 periods. The transformer aging has been calculated following the procedure suggested in the IEC 60076-7 standard and the relevant code has been developed using MATLAB.

To demonstrate the proposed methodology, a sample neighborhood consisting of 4 houses that are supplied by a $25 \mathrm{kVA}$ single phase pole mounted transformer as a local part of the distribution system is considered the parameters of which are presented in Table I [23]. It should be noted that the distribution system can use medium or low voltage regarding the consumer type and system configuration. There are 
TABLE II

Household Appliances Data

\begin{tabular}{lc}
\hline Appliance & Rated Power $[\mathbf{k W}]$ \\
\hline Refrigerator & 1.67 \\
Iron & 2.4 \\
Toaster & 0.8 \\
Kettle & 2 \\
Hairdryer & 1.8 \\
Telephone & 0.005 \\
TV & 0.083 \\
Desktop Computer & 0.15 \\
Air Conditioner & 1.14 \\
Hair Straightener & 0.055 \\
Oven & 2.4 \\
Microwave & 1.2 \\
Printer & 0.011 \\
Cooker hood & 0.225 \\
Lighting & 0.1 \\
Other (fixed) & 0.1 \\
\hline
\end{tabular}

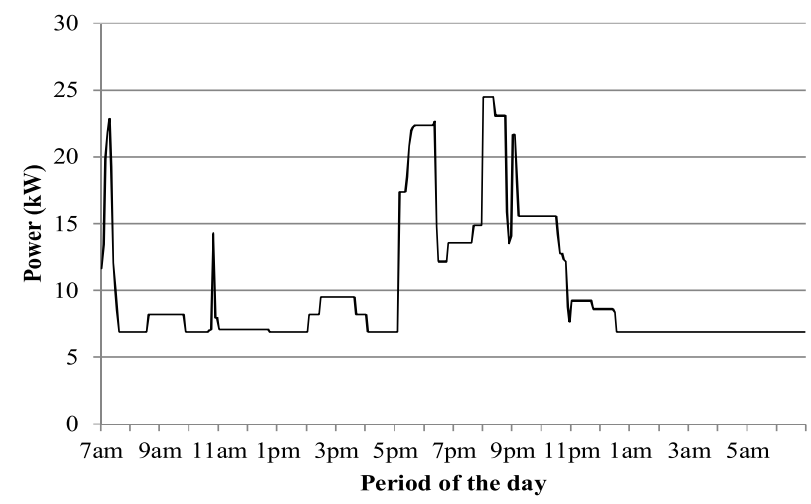

Fig. 2. Inelastic load of the neighborhood.

also international and regional differences as regards system configurations used for power distribution. The structure in Fig. 1 considers a split phase low voltage distribution system which is typical in the U.S., Japan, Canada, etc. [24], [25].

The houses are assumed to host different kinds of consumers with different load profiles. These load profiles are created considering several typical domestic appliances the nominal power of which is presented in Table II [26].

The total inelastic load profile of the neighborhood is portrayed in Fig. 2. Furthermore, each household has a battery based ESS and a rooftop PV installation. Since the households are considered to be close to each other, a PV power curve normalized per $1 \mathrm{~kW}$ of installed capacity, is used for all the houses, measured in the smart household prototype in Yildiz Technical University, during the summer of 2013, assuming random small deviations that could be possibly caused by differences in the efficiency of the PV systems, for example, due to dirty PV panel surfaces etc.

The PV production for the 4 households is presented in Fig. 3. Also, the recorded temperature for this day is portrayed in Fig. 4.

There are already different types of EVs available on the market. Eight different EVs are considered in this study and

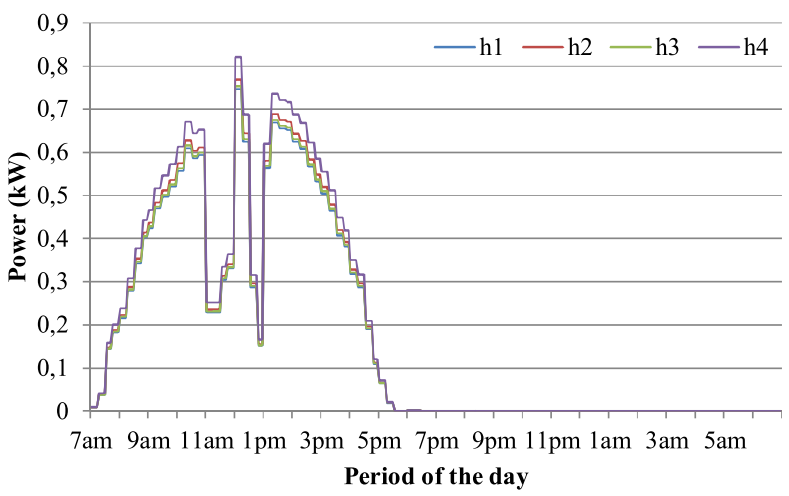

Fig. 3. PV power production of the households.

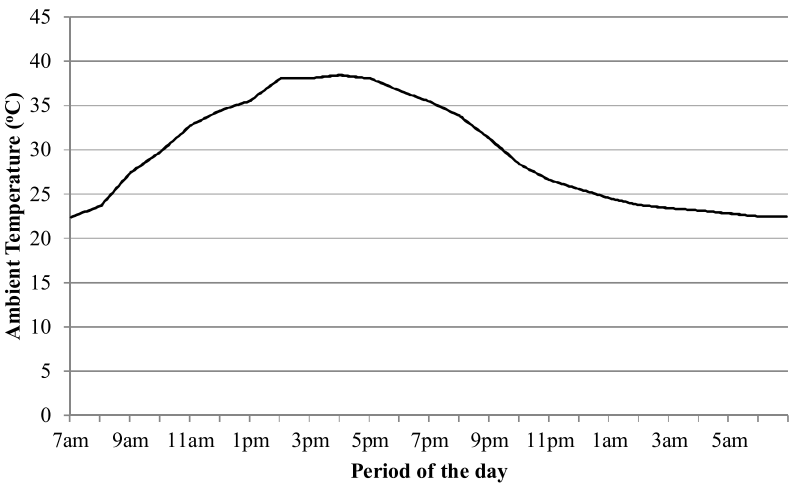

Fig. 4. Ambient Temperature.

TABLE III EV PARAMETERS

\begin{tabular}{lcc}
\hline & $\begin{array}{c}\text { Battery capacity } \\
{[\mathbf{k W h}]}\end{array}$ & $\begin{array}{c}\text { Charging/discharging rate } \\
{[\mathbf{k W}]}\end{array}$ \\
\hline BMW i3 & 22 & 6.6 \\
Chevy Volt & 17 & 3.3 \\
Ford Focus Electric & 23 & 6.6 \\
Mercedes B-Class & 28 & 10 \\
Kia Soul EV & 27 & 6.6 \\
Mitsubishi i-MIEV & 16 & 3.3 \\
Tesla Model-S & 85 & 10 \\
Volkswagen E-Golf & 24 & 7.2 \\
\hline
\end{tabular}

TABLE IV

CASE STUdies

\begin{tabular}{llcc}
\hline & Case-1 & Case-2 & Case-3 \\
\hline House 1 & No EV & Chevy Volt & Mercedes B-Class \\
House 2 & No EV & BMW i3 & Kia Soul EV \\
House 3 & No EV & Mitsubishi I-MIEV & Volkswagen E-Golf \\
House 4 & No EV & Ford Focus Electric & Tesla Model-S \\
\hline
\end{tabular}

the relevant EV data are provided in Table III. Besides, three different cases are evaluated with respect to different EV type ownership for each household as presented in Table IV.

Data concerning the EV, the PV and the ESS of each household are presented in Table V. These assets may be also used to partly or fully cover household energy needs through V2H, energy storage system to home (ESS2H) and 
TABLE V

Asset Data OF EACH Household

\begin{tabular}{|c|c|c|c|c|}
\hline & House 1 & House 2 & House 3 & House 4 \\
\hline \multicolumn{5}{|c|}{ Electric Vehicle } \\
\hline $\begin{array}{l}\text { Charging/discharging } \\
\text { efficiency [\%] }\end{array}$ & \multicolumn{4}{|c|}{95} \\
\hline Arrival time & \multicolumn{4}{|c|}{$5: 08 \mathrm{pm}$} \\
\hline \multicolumn{5}{|c|}{ PV Installation } \\
\hline \multirow[t]{2}{*}{$\begin{array}{l}\text { Installed capacity } \\
{[\mathrm{kW}]}\end{array}$} & \multicolumn{4}{|c|}{1} \\
\hline & \multicolumn{3}{|c|}{ Energy Storage System } & \\
\hline $\begin{array}{l}\text { Battery capacity } \\
{[\mathrm{kWh}]} \\
\text { Maximum }\end{array}$ & 3 & 3 & 2.4 & 2.4 \\
\hline $\begin{array}{l}\text { Charging/Discharging } \\
\text { rate }[\mathrm{kW}]\end{array}$ & \multicolumn{4}{|c|}{0.6} \\
\hline Initial SOE [\%] & 50 & 50 & 62.5 & 62.5 \\
\hline Minimum SOE [\%] & 25 & 25 & 41.6 & 41.6 \\
\hline $\begin{array}{l}\text { Charging/discharging } \\
\text { efficiency [\%] }\end{array}$ & \multicolumn{4}{|c|}{95} \\
\hline
\end{tabular}

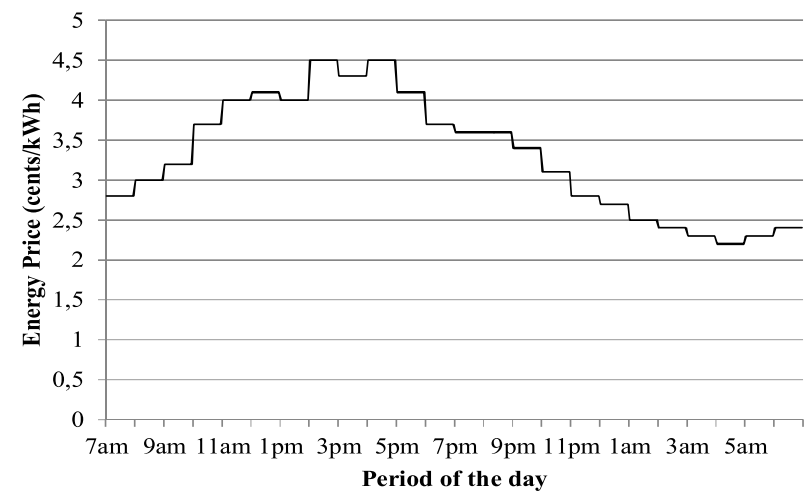

Fig. 5. Hourly energy price signal.

$\mathrm{PV}$ to home $(\mathrm{PV} 2 \mathrm{H})$ options. The retailer announces a price signal for the $24 \mathrm{~h}$ of the optimization horizon as displayed in Fig. 5.

\section{B. Simulation and Results}

As mentioned before, in order to evaluate the impacts of incentive-based DR activities on transformer loading, three test cases considering different EV types are presented.

It is to be noted that another issue related to EVs that can be considered in the mentioned case studies, is the time and location based uncertainty of EV integration to DS, which is likely to pose a considerable challenge to the distribution system operator in the future together with the expected increase in EV penetration [27]. However, this study follows a deterministic framework in which the impacts of EV based uncertainty are not considered.

Case 1 does not consider EV availability and the relevant results are depicted in Fig. 6. As it can be observed, no overloading occurs as no extra EV charging load exists. The PV and ESS partly cover the inelastic load of each household. As a result, a reduction in the transformer loading is noticed especially from 9 am to $5 \mathrm{pm}$ during which the electricity prices are relatively high. Furthermore, before 9 am, the ESSs of the

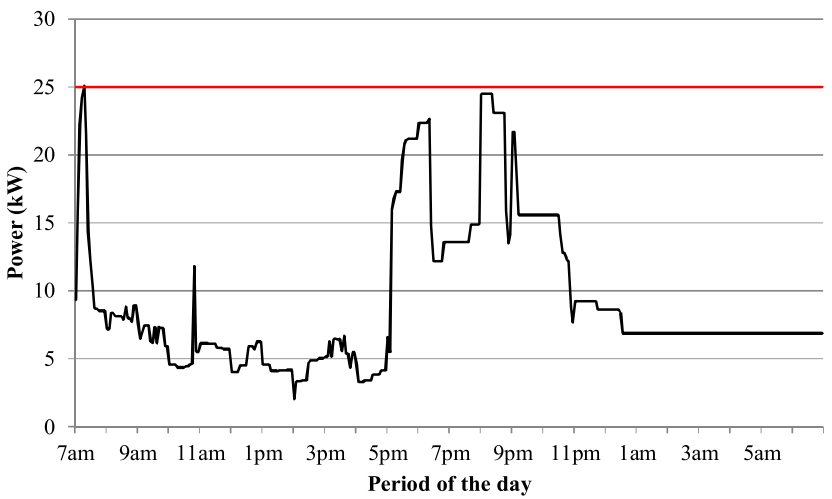

Fig. 6. Total transformer load for Case 1.

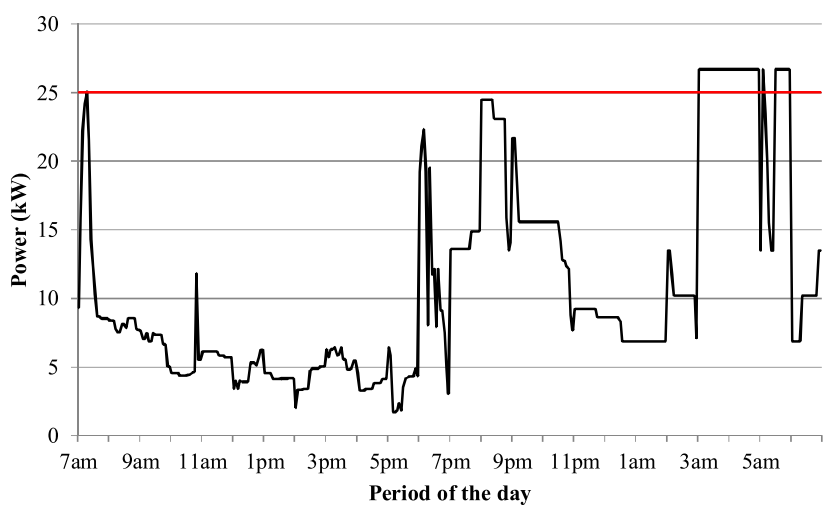

Fig. 7. Total transformer load for Case 2.

households are charging in order to be able to provide this power later, causing a peak to the transformer loading.

In Case 2 each household is considered to possess a relatively small-sized EV. The relevant results are depicted in Fig. 7. Evidently, an excessive transformer loading occurs, reaching nearly $110 \%$ for several late-night periods, especially during the lowest price hours, even if the EV capacities are relatively low in this test case. Another point to be observed is that the inelastic load is partially covered by the $\mathrm{V} 2 \mathrm{H}$ option of EVs during the periods after the arrival time of the EVs because of the higher prices the hold during these periods in comparison with the prices in later periods.

Case 3 results in the transformer loading shown in Fig. 8. This test case is relatively worse in terms of EV capacities that have the capability of being charged with greater power levels than the EVs considered in Case 2.

However, the greater the EV capacity is, the greater the opportunity of covering a more significant portion of the household power requirements by V2H option. This results in lower total transformer loading, especially in higher price periods during which using available EV energy to partly cover the household load and charge later is more profitable than procuring power from the grid. As expected, the capability of greater charging power levels leads to transformer overloading with longer duration and significantly higher levels (exceeding 160\%) in comparison with Case 2. This is likely to accelerate the transformer unit aging, a fact that should be examined further with the analysis of the transformer hot-spot temperature. 


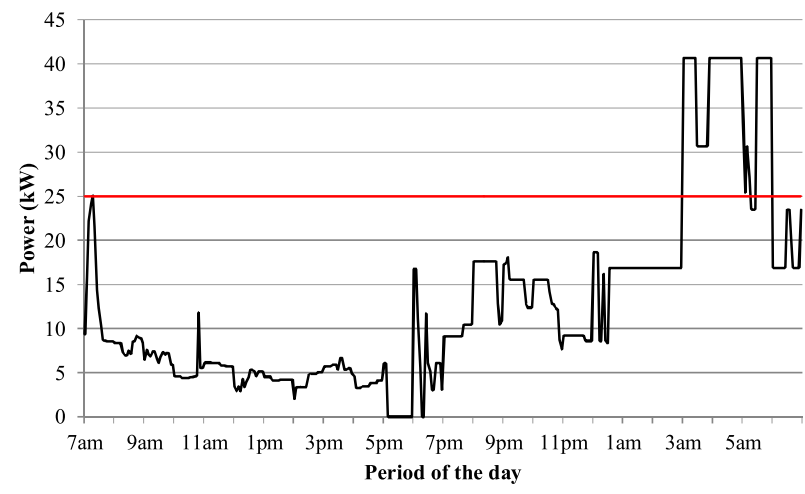

Fig. 8. Total transformer load for Case 3.

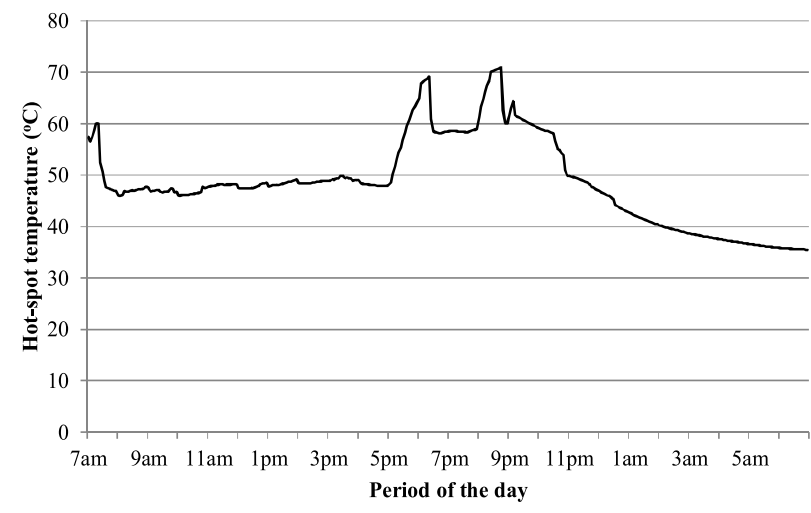

Fig. 9. Transformer hot-spot temperature for Case 1.

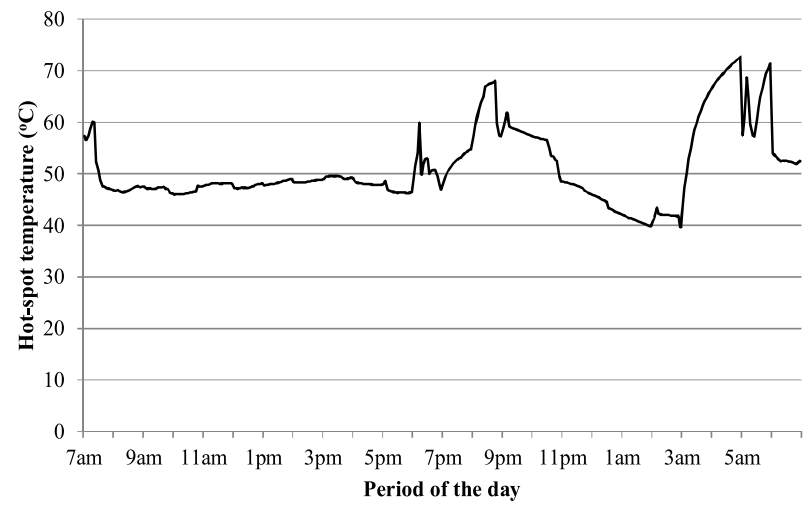

Fig. 10. Transformer hot-spot temperature for Case 2 .

In this regard, the hot-spot temperature of the transformer for the three test cases is presented in Figs. 9-11, respectively. Case 1 results in acceptable levels of temperature increase in the transformer unit while Case 2 and Case 3 boost the temperature variations due to the increasing requirement of charging power levels, especially due to the choice of EMS to charge the EV batteries after midnight due to the relatively lower prices during these periods. Even if each household owner benefits from such actions of their EMS in terms of total cost, the distribution transformer faces increasing stress that is very likely to cause more rapid aging of the insulation.

Table VI presents the relevant equivalent aging for each test case. As expected, excessive power drawn from the grid through the transformer unit results in a significant increase in

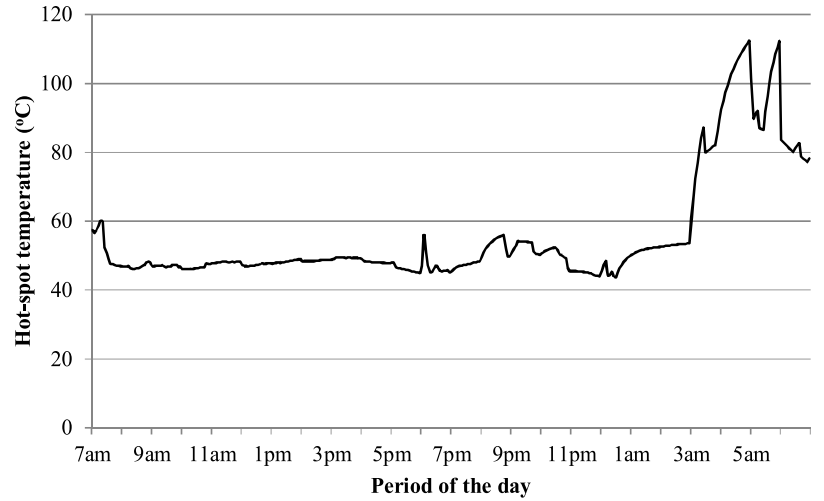

Fig. 11. Transformer hot-spot temperature for Case 3.

TABLE VI Aging Results

\begin{tabular}{|c|c|c|}
\hline \multicolumn{3}{|c|}{ Aging in equivalent hours [h] } \\
\hline & With V2H option & Without $\mathrm{V} 2 \mathrm{H}$ option \\
\hline Case-1 & 1.68 & 1.68 \\
\hline Case-2 & 2.23 & 2.05 \\
\hline Case-3 & 67.84 & 16.77 \\
\hline
\end{tabular}

transformer aging in Case 3 in comparison with Cases 1 and 2. It may be also observed that the increase in EV capacities results in an undesired decrease in transformer lifetime that is a main concern for the DS Operators, although it guarantees that EVs can cover longer travelling distances and as a result may promote the electrification of personal transport and the smart grid enabling technologies in general.

As a different analysis, the previous case studies are reevaluated by considering that the V2H option of the EVs is not available. Normally, the availability of the V2H option allows for higher flexibility for the EMS of the end-user that may also decide to cover a part of the household load requirements from the EV, when the price of procuring power from the grid is high. However, this will in turn result in greater energy requirements to fully charge the EV battery in order to satisfy the comfort conditions of the EV owner, which means a greater peak in the total load of the transformer when the power procurement costs are lower, typically after midnight. Thus, the utilization of the $\mathrm{V} 2 \mathrm{H}$ option is very likely to have a more adverse effect on the loading and the thermal stress of the distribution transformer.

The results regarding the total transformer load and the transformer hot-spot temperature considering that $\mathrm{V} 2 \mathrm{H}$ option is not available are presented in Figs. 12 and 13 for Cases 2 and 3, respectively. As Case 1 does not consider EV availability, the results that were previously depicted in Figs. 6 and 9 do not change and thus are not repeated. It can be seen from the total transformer load for both cases that the observed power peaks are considerably lower and with shorter duration. This is caused by the fact that since no discharge is possible when the EV is at home, less amount of energy is required to charge the EV batteries.

The impact on reduction of power peaks also results in less increase in transformer hot-spot temperature as it can be observed in Fig. 13. Thus, a significant reduction in the aging 


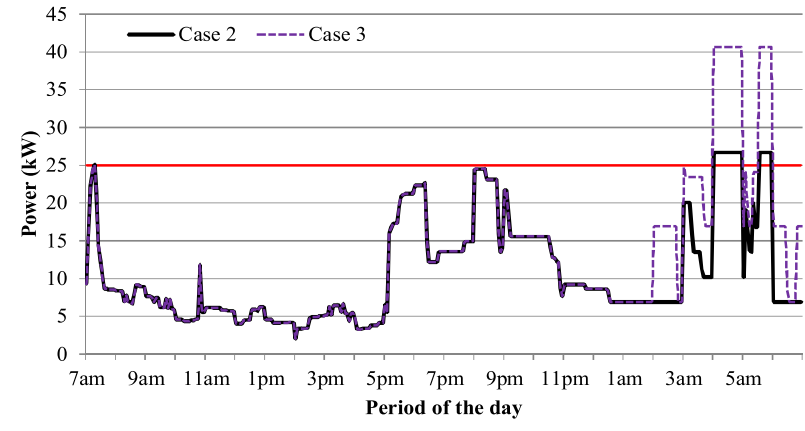

Fig. 12. Total transformer load for Cases 2 and 3 without V2H option.

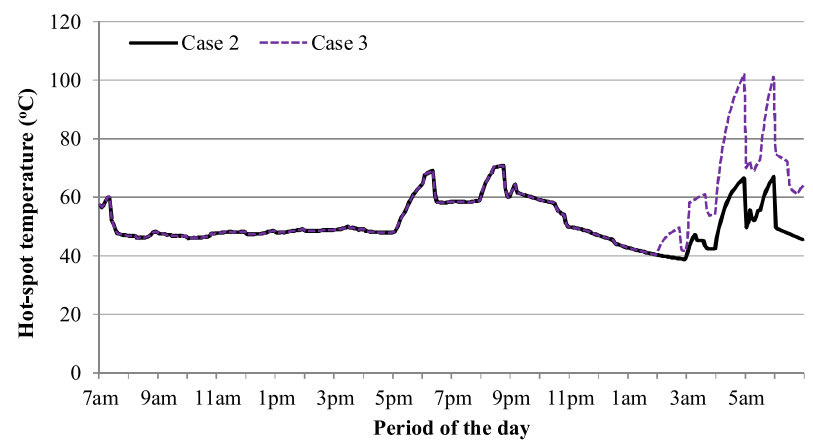

Fig. 13. Transformer hot-spot temperature for Cases 2 and 3 without V2H option.

TABLE VII

ENERGy Procurement Cost OF DifFERENT HouseholdS

\begin{tabular}{lcccccccc}
\hline & \multicolumn{3}{c}{ With V2H option } & \multicolumn{4}{c}{ Without V2H option } \\
\hline & H1 & H2 & H3 & H4 & H1 & H2 & H3 & H4 \\
\cline { 2 - 9 } Case 1 & 1.83 & 1.83 & 1.83 & 1.80 & 1.83 & 1.83 & 1.83 & 1.80 \\
Case 2 & 1.98 & 2.01 & 1.97 & 1.99 & 2.03 & 2.09 & 2.02 & 2.07 \\
Case 3 & 2.06 & 2.06 & 2.03 & 2.65 & 2.16 & 2.15 & 2.11 & 2.83 \\
\hline
\end{tabular}

of the transformer is observed as it can be seen in Table VI for both the Cases 2 and 3 when the V2H option is not available. In fact, no aging acceleration is noticed and therefore, the observed overloading may be considered acceptable.

Furthermore, the total energy procurement cost considering the availability of the V2H option is compared with the corresponding costs for the case in which the $\mathrm{V} 2 \mathrm{H}$ option is not available and the relevant results are presented in Table VII. End-users benefit from the V2H option due to the possibility of utilizing the energy stored in the EV to cover portion of the household load during higher price periods.

This comparison indicates that even if the home owners can benefit from the $\mathrm{V} 2 \mathrm{H}$ option and increased levels of smart grid enabling technologies, the DS may encounter detrimental results in terms of facing extra stress and aging of assets, etc., which clearly depicts that the deployment of such new technologies in power system should be carefully planned in order to balance the benefits for both end-users and energy suppliers.

\section{On the Efficiency of the Pricing Mechanism}

In the pricing mechanism adopted in this study, it is considered that the price of electricity is different during each hour of the day and is known to the consumer before the actual day in which the consumption takes place. Through dynamic pricing consumers are directly exposed to the variability of the cost in the wholesale day-ahead energy market. Currently, two noticeable dynamic pricing programs engaging residential end-users exist in the U.S., one by Pennsylvania New Jersey Maryland Interconnection (PJM) [28] and one by the Midcontinent ISO (MISO) [29]. In both programs the dayahead market prices are known to the consumer one day before the actual power delivery; however, the way in which they actually price the consumers differs. In the program offered by PJM, the end-users are priced according to the real-time prices that are settled in the end of each hour in the actual dispatch day and are calculated by averaging the 5-minute prices of that hour, while in the program offered by MISO consumers are priced according to the day-ahead prices. In this paper, the pricing mechanism that is used is similar to the relevant MISO program.

Although dynamic pricing (e.g., real-time pricing) is generally considered to reflect the very short term cost of electricity, the efficiency of this pricing mechanism is often questioned mainly due to two reasons [30]: 1) residential end-users (that are the primary target group of such programs) do not necessarily follow a rational economical model as regards that consumption of electricity, i.e., a consumer may still be willing to consume electricity at peak hours, and 2) the asymmetry between the communication of the prices and the response of the end-user.

Evidently, the very short term costs of electricity are better captured by programs that price the end-user based on the prices produced by real-time markets that are cleared on a very short term basis (e.g., several minutes) rather than by those that price the end user according to the day-ahead market prices; This is the reason why the energy prices in this study, that follow the latter mechanism, do not reflect the power consumption peaks in the early morning hours due to the EV charging; however, the first type of dynamic pricing programs present the disadvantage of exposing consumers to uncertainty, since the electricity price is settled after the consumption interval. As a result, this type of programs may compromise the incentives provided to the consumers in order to motivate them to enroll, since the rationale behind dynamic pricing is that consumers would exercise price arbitrage, which in turn depends on the differences of the prices within the day, which in this case would not be known a priori. In such cases, uncertainty management techniques would be necessary in order to predict the electricity prices, which may not be justifiable for residential consumers, in terms of complexity and computational burden, because the welfare gain of their participation in dynamic pricing schemes is little.

In order to confront the deficiencies of the pricing mechanism the following are suggested:

1) Development of advanced models that predict the response of the end-users based on exogenous factors such as the weather and the time delay between the communication of the energy prices and the actual response [30]. 
TABLE VIII

COMPUTATIONAL STATISTICS

\begin{tabular}{lc}
\hline Equations & 4281 \\
Variables & 4017 \\
Discrete variables & 568 \\
\hline
\end{tabular}

2) Development of residential consumption coordination strategies that consider distribution system constraints [17], [31] or the interaction of the transformer management unit and the EMS [32] together with dynamic pricing mechanisms.

\section{Computational Statistics}

The computational statistics of each optimization subproblem are provided in Table VIII. The total solution time, considering an optimality gap of $0 \%$, is 1 sec on a modern laptop computer (i7 at $2.4 \mathrm{GHz}, 4 \mathrm{~GB}$ RAM, 64bit Windows).

Note that the separable form of Algorithm 1 allows for distributed computing techniques to be applied and as a result the privacy of the end-users is preserved.

As the computational capabilities of embedded systems that are needed to implement EMS and monitoring systems increase, it appears that such complex algorithms will be practically applicable even for large scale systems.

\section{CONCLUSION}

In this study, an analysis of the impacts of price-incentive based DR on a neighborhood distribution transformer aging has been performed. A MILP model of a neighborhood composed of smart households with different end-user profiles was developed. The availability of a distributed generation unit, an ESS, and an EV considering also PV2H, ESS2H and $\mathrm{V} 2 \mathrm{H}$ capabilities has been modeled. Furthermore, a thermal model of the transformer unit serving this neighborhood for transformer aging evaluation has been provided based on existing standards. The main contribution of the study was to combine the impacts of price-responsive residential endusers based DR schemes and relevant impacts on transformer aging for different case studies based on different capacities of EVs. The availability of V2H option has also been discussed in the comparative analysis. The obtained results for different case studies demonstrated the significant adverse effects of extra EV loads combined with price-based DR activities, which strive to shift as much load as possible to low-price hours. The aging of the transformer has shown a tremendous increase with the increase in the capacity of the EV. Besides, the negative impacts of $\mathrm{V} 2 \mathrm{H}$ option on the transformer unit extra loading and the relevant increase in aging have also been comparatively demonstrated. Yet, V2H option availability provided more flexibility for EMS of each household to lower total prices by covering some portion of the household load from EVs. It can be concluded that while greater EV capacities and the availability of V2H option allowed residential end-user EMS to benefit more from price-incentive based DR schemes, these options may adversely affect DS reliability by stressing more DS assets. Thus, DR schemes can also be examined from such a perspective, that is, from DS Operator point of view. As a future study, the authors aim to provide a two-side optimization approach to investigate the appropriate balance between end-user benefits and DS operational considerations. Besides, the implementation of the proposed structure to study a greater part of the distribution system composed of multiple neighborhoods and also considering the aging effect of loading on other distribution system assets will be the topic of a future study.

\section{REFERENCES}

[1] M. Falahi, H.-M. Chou, M. Ehsani, L. Xie, and K. L. Butler-Purry, "Potential power quality benefits of electric vehicles," IEEE Trans. Sustain. Energy, vol. 4, no. 4, pp. 1016-1023, Oct. 2013.

[2] Z. Darabi and M. Ferdowsi, "Aggregated impact of plug-in hybrid electric vehicles on electricity demand profile," IEEE Trans. Sustain. Energy, vol. 2, no. 4, pp. 501-508, Oct. 2011.

[3] S. Rezaee, E. Farjah, and B. Khorramdel, "Probabilistic analysis of plug-in electric vehicles impact on electrical grid through homes and parking lots," IEEE Trans. Sustain. Energy, vol. 4, no. 4, pp. 1024-1033, Oct. 2013

[4] O. Erdinc, N. G. Paterakis, T. D. P. Mendes, A. G. Bakirtzis, and J. P. S. Catalão, "Smart household operation considering bi-directional EV and ESS utilization by real-time pricing-based DR," IEEE Trans. Smart Grid, vol. 6, no. 3, pp. 1281-1291, May 2015.

[5] U. C. Chukwu and S. M. Mahajan, "Real-time management of power systems with V2G facility for smart-grid applications," IEEE Trans. Sustain. Energy, vol. 5, no. 2, pp. 558-566, Apr. 2014.

[6] A. Alahyari, M. Fotuhi-Firuzabad, and M. Rastegar, "Incorporating customer reliability cost in PEV charge scheduling schemes considering vehicle-to-home capability," IEEE Trans. Veh. Technol., vol. 64, no. 7, pp. 2783-2791, Jul. 2015.

[7] Z. Chen, L. Wu, and Y. Fu, "Real-time price-based demand response management for residential appliances via stochastic optimization and robust optimization," IEEE Trans. Smart Grid, vol. 3, no. 3, pp. 1822-1831, Dec. 2012.

[8] K. M. Tsui and S. C. Chan, "Demand response optimization for smart home scheduling under real-time pricing," IEEE Trans. Smart Grid, vol. 3, no. 4, pp. 1812-1821, Dec. 2012.

[9] M. Pipattanasomporn, M. Kuzlu, and S. Rahman, "An algorithm for intelligent home energy management and demand response analysis," IEEE Trans. Smart Grid, vol. 3, no. 4, pp. 2166-2173, Dec. 2012.

[10] M. Kuzlu, M. Pipattanasomporn, and S. Rahman, "Hardware demonstration of a home energy management system for demand response applications," IEEE Trans. Smart Grid, vol. 3, no. 4, pp. 1704-1711, Dec. 2012.

[11] S. Shao, M. Pipattanasomporn, and S. Rahman, "Demand response as a load shaping tool in an intelligent grid with electric vehicles," IEEE Trans. Smart Grid, vol. 2, no. 4, pp. 624-631, Dec. 2011.

[12] F. De Angelis et al., "Optimal home energy management under dynamic electrical and thermal constraints," IEEE Trans. Ind. Informat., vol. 9, no. 3, pp. 1518-1527, Aug. 2013.

[13] X. Chen, T. Wei, and S. Hu, "Uncertainty-aware household appliance scheduling considering dynamic electricity pricing in smart home," IEEE Trans. Smart Grid, vol. 4, no. 2, pp. 932-941, Jun. 2013.

[14] Q. Gong, S. Midlam-Mohler, V. Marano, and G. Rizzoni, "Study of PEV charging on residential distribution transformer life," IEEE Trans. Smart Grid, vol. 3, no. 1, pp. 404-412, Mar. 2012.

[15] R. Vicini, O. Micheloud, H. Kumar, and A. Kwasinski, "Transformer and home energy management systems to lessen electrical vehicle impact on the grid," IET Gener. Transm. Distrib., vol. 6, no. 12, pp. 1202-1208, Dec. 2012.

[16] A. D. Hilshey, P. D. H. Hines, P. Rezaei, and J. R. Dowds, "Estimating the impact of electric vehicle smart charging on distribution transformer ageing," IEEE Trans. Smart Grid, vol. 4, no. 2, pp. 905-913, Jun. 2013

[17] N. G. Paterakis, S. F. Santos, J. P. S. Catalão, O. Erdinc, and A. G. Bakirtzis, "Coordination of smart-household activities for the efficient operation of intelligent distribution systems," in Proc. 5th IEEE PES Innov. Smart Grid Technol. Europe Conf. (ISGT-Europe), Istanbul, Turkey, Oct. 2014, pp. 1-6.

[18] Loading Guide for Oil-Immersed Power Transformers, IEC Standard 60076-7, 2005.

[19] Guide for Loading Mineral-Oil-Immersed Power Transformers, IEEE Standard C57.91-1995, 1995. 
[20] H. Pezeshki, P. J. Wolfs, and G. Ledwich, "Impact of high PV penetration on distribution transformer insulation life," IEEE Trans. Power Del., vol. 29, no. 3, pp. 1212-1220, Jun. 2014.

[21] H. Turker, S. Bacha, D. Chatroux, and A. Hably, "Low-voltage transformer loss-of-life assessments for a high penetration of plug-in hybrid electric vehicles (PHEVs)," IEEE Trans. Power Del., vol. 27, no. 3, pp. 1323-1331, Jul. 2012

[22] K. Qian, C. Zhou, and Y. Yuan, "Impacts of high penetration level of fully electric vehicles charging loads on the thermal ageing of power transformers," Int. J. Elect. Power Energy Syst., vol. 65, pp. 102-112, Feb. 2015.

[23] M. Kuss, T. Markel, and W. Kramer, "Application of distribution transformer thermal life models to electrified vehicle charging loads using Monte-Carlo method," in Proc. 25th World Battery Hybrid Fuel Cell Elect. Veh. Symp. Exhibit., Shenzhen, China, 2010, pp. 1-8

[24] M. Weigand, S. Bohn, D. Beyer, and M. Agsten, "Integration of electric vehicle charging into an international and environment-friendly context," SAE Int. J. Passenger Cars Electron. Elect. Syst., vol. 7, pp. 536-543, Aug. 2014.

[25] S. Bohn, M. Agsten, A. Dubey, and S. Santoso, "A comparative analysis of PEV charging impacts-An international perspective," Tech. Rep. 2015-01-0300, 2015. Doi: 10.4271/2015-01-0300.

[26] A. Tascikaraoglu, A. R. Boynuegri, and M. Uzunoglu, "A demand side management strategy based on forecasting of residential renewable sources: A smart home system in Turkey," Appl. Energy, vol. 80, pp. 309-320, Sep. 2014.

[27] S. Bohn, R. Feustel, and M. Agsten, "MC-based risk analysis on the capacity of distribution grids to charge PEVs on 3-ph 0.4-kV distribution grids considering time and location uncertainties," SAE Int. J. Passenger. Cars Electron. Elect. Syst., vol. 8, pp. 394-400, Aug. 2015.

[28] (Nov. 20, 2015). ComEd Residential Real-Time Pricing Program. [Online]. Available: http://rrtp.comed.com

[29] Power Smart Pricing. [Online]. Available: http://www.powersmartpricing.org

[30] N. O'Connell, P. Pinson, H. Madsen, and M. O'Malley, "Benefits and challenges of electrical demand response: A critical review," Renew. Sustain. Energy Rev., vol. 39, pp. 686-699, Nov. 2014.

[31] N. G. Paterakis, M. F. Medeiros, J. P. S. Catalão, and O. Erdinc, "Distribution system operation enhancement through household consumption coordination in a dynamic pricing environment," in Proc. IEEE PowerTech, Eindhoven, The Netherlands, 2015, pp. 1-6.

[32] N. G. Paterakis, I. N. Pappi, J. P. S. Catalão, and O. Erdinc, "Optimal operational and economical coordination strategy for a smart neighborhood," in Proc. IEEE PowerTech, Eindhoven, The Netherlands, 2015, pp. 1-6.

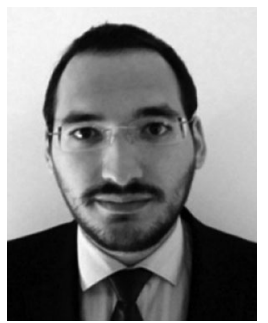

Nikolaos G. Paterakis (S'14-M'16) received the Dipl. Eng. degree from the Department of Electrical and Computer Engineering, Aristotle University of Thessaloniki, Thessaloniki, Greece, in 2013 In September 2013, he joined the Department of Electromechanical Engineering, University of Beira Interior, Covilhã, Portugal, where he pursued the Ph.D. degree working under the EU FP7 funded SiNGULAR Project. Since October 2015, he has been a Postdoctoral Fellow with the Department of Electrical Engineering, Eindhoven University of Technology, Eindhoven, The Netherlands. His research interests include power systems operation and planning, renewable energy integration, ancillary services, demand response, and smart grid applications.

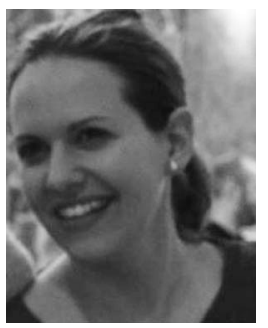

Iliana N. Pappi received the Dipl.Eng. degree from the Department of Electrical and Computer Engineering, Aristotle University of Thessaloniki, Thessaloniki, Greece, in 2012. She is currently working as a Research Associate with the University of Beira Interior, Covilhã, Portugal, under the EU FP7 funded Project "Smart and Sustainable Insular Electricity Grids Under Large-Scale Renewable Integration.” Her research interests include smart grid enabling technologies, smart-household operation and decision-making, energy efficiency in buildings, load profiling, and integration of smart grid solutions into the electrical grid.

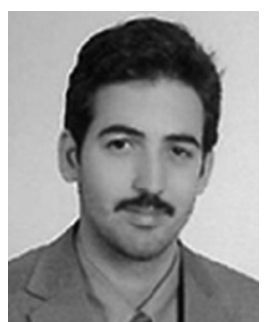

Ozan Erdinç (M'14) received the B.Sc., M.Sc., and $\mathrm{Ph} . \mathrm{D}$. degrees from Yildiz Technical University, Istanbul, Turkey, in 2007, 2009, and 2012, respectively. Until May 2013, he worked in the private sector in different positions including electrical installations, renewable energy investments, and Procurement Expert. He has been a Postdoctoral Fellow with the University of Beira Interior, Covilhã, Portugal, since May 2013, under the EU FP7 funded Smart and Sustainable Insular Electricity Grids Under Large-Scale Renewable Integration Project. From February 2014 to January 2015, he worked as an Assistant Professor with the Electrical-Electronics Engineering Department, Istanbul Arel University, Istanbul, Turkey. In January 2015, he joined the Electrical Engineering Department, Yildiz Technical University, Istanbul, as an Assistant Professor. He is currently also a Researcher with INESC-ID, Lisbon. His research interests are hybrid renewable energy systems, electric vehicles, power system operation, and smart grid technologies.

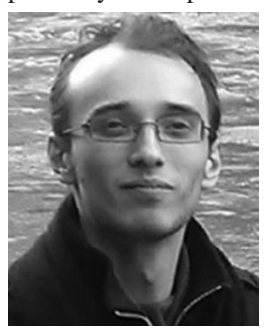

Radu Godina received the B.Sc. and M.Sc. degrees from the University of Beira Interior (UBI), Covilhã, Portugal, in 2011 and 2013, respectively. He worked as an intern in the automotive industry until 2013 and he has been a Ph.D. Researcher with UBI, since 2013 under the EU FP7 funded Project "Smart and Sustainable Insular Electricity Grids Under Large-Scale Renewable Integration.” His research interests include renewable energy systems, power transformer operation and aging, electric vehicles, and control theory.

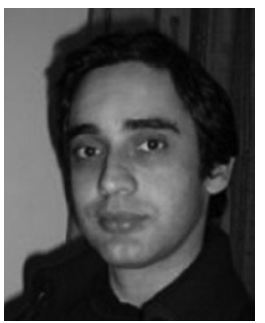

Eduardo M. G. Rodrigues received the degree in electromechanical engineering from the University of Beira Interior (UBI), Covilhã. Before becoming a Ph.D. Researcher with UBI under the EU FP7 funded Project "Smart and Sustainable Insular Electricity Grids Under Large-Scale Renewable Integration," he gained significant industrial experience in different industrial sectors, namely in control valves manufacturing and automotive industry and in steel casting foundries, covering different areas such as quality management systems, product development, maintenance engineering in heavy mechanical sector, and field service with MW-size power converters. His research interests are maintenance engineering, advanced industrial power electronics applications, instrumentation and signal acquisition, digital signal processing, and advanced control techniques implementation.

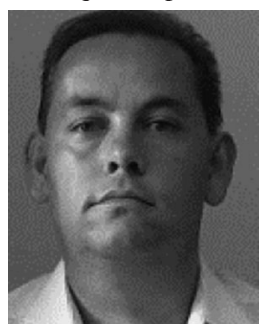

João P. S. Catalão (M'04-SM'12) received the M.Sc. degree from Instituto Superior Técnico, Lisbon, Portugal, in 2003, and the Ph.D. and Habilitation degrees for Full Professor ("Agregação") from the University of Beira Interior (UBI), Covilhã, Portugal, in 2007 and 2013, respectively.

$\mathrm{He}$ is currently a Professor with the Faculty of Engineering, University of Porto, Porto, Portugal, and a Researcher with INESC-ID, Lisbon, and C-MAST/UBI. He has been the Primary Coordinator of the EU FP7 funded Project "Smart and Sustainable Insular Electricity Grids Under Large-Scale Renewable Integration.” He has authored or co-authored over 400 publications, including, among others, 130 journal papers, 250 conference proceedings papers, and 20 book chapters, with an H-index of 25 (according to Google Scholar), and has supervised over 30 postdoctorates, Ph.D., and M.Sc. students. He has edited the books Electric Power Systems: Advanced Forecasting Techniques and Optimal Generation Scheduling (CRC Press, 2012) and Smart and Sustainable Power Systems: Operations, Planning and Economics of Insular Electricity Grids (CRC Press, 2015). His research interests include power system operations and planning, hydro and thermal scheduling, wind and price forecasting, distributed renewable generation, demand response, and smart grids.

Prof. Catalão was a recipient of the 2011 Scientific Merit Award UBIFE/Santander Universities, the 2012 Scientific Award UTL/Santander Totta, and four best paper awards at the IEEE conferences. He is an Editor of the IEEE TRANSACTIONS ON SMART GRID and the IEEE TRANSACTIONS ON Sustainable Energy, and an Associate Editor of IET Renewable Power Generation. He was the Guest Editor-in-Chief of the Special Section on Real-Time Demand Response of the IEEE TRANSACTIONS ON SMART GRID, published in 2012, and he is currently the Guest Editor-in-Chief of the Special Section on Reserve and Flexibility for Handling Variability and Uncertainty of Renewable Generation of the IEEE TRANSACTIONS ON SUSTAINABLE ENERGY. 